\title{
OUTCOME OF PRIMARY PTERYGIUM SURGERY USING INFERIOR CONJUNCTIVAL AUTOGRAFT
}

Sushila Patel, ${ }^{1}$ Manita Sunam Godar, ${ }^{1}$ Binita Bhattarai Pokharel, ${ }^{1}$

\begin{abstract}
INTRODUCTION

Pterygium is a common ocular condition with prevalence varying from $0.7-39 \%$ in different population and particularly high in the tropics. Various surgical techniques including inferior conjunctival autograft are available for the treatment of pterygium. This study was done to determine the clinical profile and outcome of primary pterygium surgery using inferior conjunctival autograft.
\end{abstract}

\section{MATERIAL AND METHODS}

This was a prospective, non-comparative interventional study conducted over a period of one year from January to December 2019 in patients with primary pterygium who presented at cornea department of Lumbini Eye Institute and Research Center, Bhairahawa, Nepal. All the patients with primary pterygium, a detail clinical history and examination were done. Pterygium was excised using inferior conjunctival auto grafting and followed regularly over a period of three months.

\section{RESULTS}

We analysed 626 eyes in 619 patients with primary pterygium in which mean age was $44.63 \pm 13.84$ years. There were 363 (58.64\%) females. Majority of our patients were housewife 350 (56.54\%) and farmer 170 (27.46\%). Mean duration of presentation was $3.59 \pm 2.87$ year. Pterygium was found mostly on nasal side $614(98.08 \%)$. Depending on the size, maximum patients had type 2 pterygium (73.80\%) followed by type 3 pterygium (18.69\%). The commonest post operative complication was raised intraocular pressure which was seen in $43(6.87 \%)$ eyes and recurrence rate was $0.64 \%$.

\section{CONCLUSION}

Primary pterygium was seen more commonly in adults in their $4^{\text {th }}-5^{\text {th }}$ decade of life with female predominance. Primary pterygium surgery using inferior conjunctival autograft is a safe and effective with very few complication and recurrence.

KEYWORDS Inferior conjunctival autograft, Primary pterygium, Recurrence of pterygium.

1. Department of Ophthalmology, Lumbini Eye Institute and Research Center, Bhairahawa, Nepal

DOI: http//doi.org/10.3126/jucms.v8i02.34244

\author{
For Correspondence \\ Dr. Sushila Patel \\ Cornea Department \\ Lumbini Eye Institute and Research Center \\ Bhairahawa, Nepal \\ Email:drsushilapatel@yahoo.com
}




\section{INTRODUCTION}

Pterygium is a triangular wing-shaped, fibrovascular, fleshy growth that originates from the conjunctiva and can spread onto the cornea. Pterygium is a common degenerative ocular surface disorder, particularly seen in the tropics. ${ }^{1}$ Prevalence of pterygium varies from country to country ranging from $0.7 \%$ to $39 \%$. $^{2-5}$ There are multiple risk factors known for the development of pterygium like exposure to ultraviolet (UV) light, wind, dust, older age, male gender, outdoor occupation and living in rural environments. ${ }^{6-9}$

Surgical excision is the main treatment of the pterygium. Various surgical techniques are available for the excision of pterygium, but no single technique is universally satisfactory in terms of recurrence rate, complication, technical simplicity, and cosmetic outcomes. Highest recurrence rate has been reported up to $89 \%$ in bare sclera technique. ${ }^{1}$ Kenyon et al described about free conjunctival autografting technique in 1985, which involves excision of the pterygium and closing of defect by harvesting of a conjunctival graft from the same eye. $^{10}$ It has reduced the recurrence rate to $5.3 \% .^{10}$ Free conjunctival autograft is mostly taken from the superior bulbar conjunctiva.

In situations like trauma, post-infection, glaucoma filtering surgery and manual small incision cataract surgery (MSICS); it is difficult to take graft from the same place because of conjunctival scarring. In such situation the graft is harvested from inferior bulbar conjunctiva. Furthermore the superior bulbar conjunctiva should be reserved for future glaucoma filtration surgery, as well as for MSICS which is still popular in developing countries. There is a large amount of data available regarding conjunctival autograft taken from superior bulbar conjunctiva. ${ }^{11,12}$ However, there is limited information available regarding the efficacy of a graft taken from the inferior conjunctiva. ${ }^{13,14}$ With this background we have conducted this study to determine the outcome of pterygium surgery using inferior conjunctival autograft and preserving the superior bulbar conjunctiva for future surgeries.

\section{MATERIAL AND METHODS}

This was a prospective, non-comparative interventional study, conducted on patients presented to the department of cornea in Lumbini Eye Institute and Research Center (LEIRC), Bhairahawa, Nepal over a period of one year from $1^{\text {st }}$ January 2019 to $31^{\text {st }}$ December 2019. Study was ethically approved by the institutional review committee of LEIRC. Written informed consent was taken from all of the patients. All the patients who presented with the primary pterygium with $\geq 16$ years of age, were enrolled in the study. We excluded the patient with $<16$ years of age, recurrent pterygium, history of ocular trauma, pseudopterygium, atypical pterygium, double headed pterygium, local inflammation or infection.
A detailed history including demographic data of age, sex, occupation, duration of presentation, history of any systemic diseases or ocular diseases were noted in all the patients. A slit lamp examination was performed to determine the pterygium size in millimetres, by measuring from the limbus to the corneal limit of the growth in the horizontal plane. Pterygium was classified as per classification mentioned by Popat et al. Type 1 - Pterygium encroaching 0-2 $\mathrm{mm}$ area on the cornea, i.e. crossing limbal margin but not reaching pupillary margin; Type 2 - Pterygium encroaching 2-4 $\mathrm{mm}$ area on the cornea, i.e. reaching upto pupillary margin but not crossing it; Type 3 Pterygium encroaching $>4 \mathrm{~mm}$ area on the cornea, i.e. crossing pupillary margin and coming in visual axis. ${ }^{15}$

Blood investigations like random blood sugar (RBS), hepatitis B surface antigen (HBsAg) and human immunodeficiency virus (HIV) test were done. One day prior to surgery, patients were started with antibiotic eye drop Moxifloxacin $0.5 \%$ and Prednisolone acetate $1 \%$ four times in a day.

\section{SURGICAL TECHNIQUE}

One of the first two investigators has performed the surgery under peribulbar block with $2 \%$ lignocaine. After painting the lids and periocular area with $5 \%$ povidone iodine and draping, a lid speculum was applied. The pterygium was dissected from the cornea using Westcott scissors from one end to another end from limbus. The part of the pterygium on the cornea was removed with Colibri and the rough surface of the corneal bed was smoothen with crescent blade. Underlying Tenon's capsule were trimmed and subconjunctival fibrous tissue under the pterygium was excised much more widely than the area covered by the pterygium using Westcott scissors. A roughly appropriate-sized graft of bare sclera from the adjacent inferior bulbar conjunctiva after blunt dissection of the conjunctiva without the Tenon's capsule was taken and rotated over the excised area and sutured with 10-0 Nylon. Chloramphenicol $1 \%$ ointment was applied at the end of surgery and operated eye was patched.

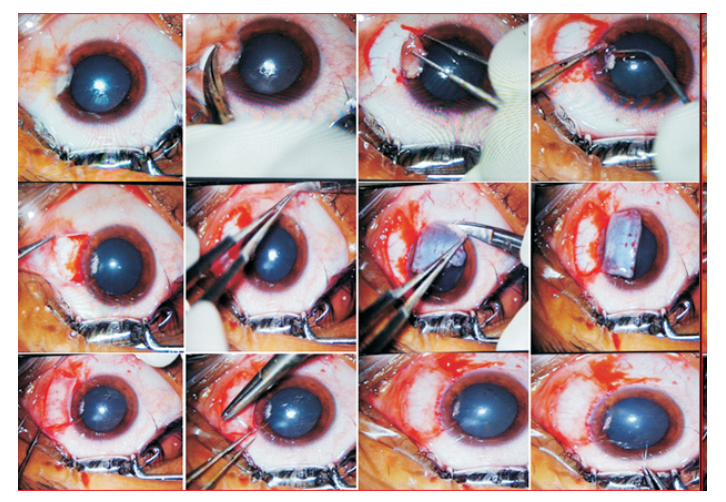

Figure 1. Showing surgical steps of primary pterygium excision using inferior conjunctival autograft 


\section{Follow up visits}

Slit lamp examination was performed on the first postoperative day and examined for graft, suture in place along with donor site of graft and topical Moxifloxacin 0.5\% and Prednisolone acetate $1 \%$ eye drops were administered as one drop four times a day for the two week and steroid was tapered until one month after 2 week. Patients also received Chloramphenicol $1 \%$ ointment two times in a day for the first 2 weeks. On postoperative day 15, we removed residual sutures if present with 26 gauge needle and plain forceps under topical anesthesia using 4\% xylocaine eye drops. We also examined the patients at 1.5 month and 3 months postoperatively, and evaluated for graft retraction, graft odema, graft necrosis, granuloma, Tenon's cyst, and recurrence.

\section{Statistical analysis}

All the data entered into Microsoft Excel spreadsheet were analyzed using SPSS ver 16.0(PC) / EpiInfo (CDC, Atlanta, GA, USA). Data were expressed as the frequency, percentage, mean, standard deviation, and range, as applicable. A p-value of less than 0.05 was indicative of statistical significance

\section{RESULTS}

In this study, 652 eyes were operated for primary pterygium surgery in 645 patients. Twenty six patients were lost in the follow up, so they were excluded in the final analysis. Seven patients underwent primary pterygium surgery in both eyes. Final analysis was done of 619 patients who were operated in 626 eyes and completed 3 months follow-up visits (Figure 2).

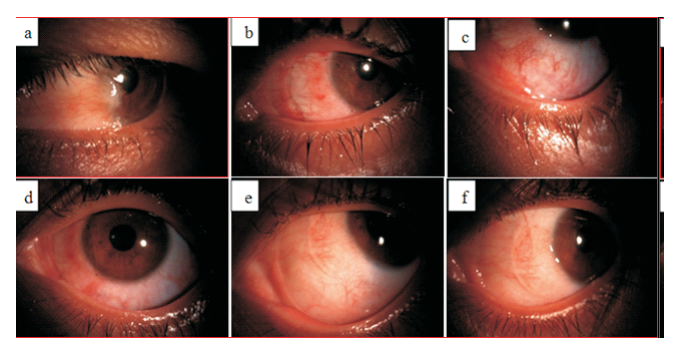

Figure 2. (a) Pre op primary pterygium (b) $1^{\text {st }}$ post op day showing the autogrft in place with 10-0 nylon suture (c) $1^{\text {st }}$ post op day showing inferior bulbar conjunctiva part from where graft was harvasted (d) $2^{\text {nd }}$ weeks post op showing graft with suture and inferior bulbar conjunctiva (e) 45 days post op showing graft and inferior bulbar conjunctiva (f) 3 months follow up

Basic characteristics of the patients are shown in Table 1. Mean age of our patients was $44.63 \pm 13.84$ years ranging from 17 to 85 years. Age distribution shows that highest incidence of pterygium was found in age group of 31-40 years (26.33\%) and least incidence was found in age group of $>80$ years $(0.32 \%)$. There were $256(41.36 \%)$ male and $363(58.64 \%)$ female.
Table 1. Demographic and preoperative characteristics

\begin{tabular}{ll}
\hline $\begin{array}{l}\text { Parameters } \\
\text { Age (yrs) }\end{array}$ & N (\%) \\
\hline$\leq 20$ & $12(1.94 \%)$ \\
$21-30$ & $99(15.99 \%)$ \\
$31-40$ & $163(26.33 \%)$ \\
$41-50$ & $155(25.04 \%)$ \\
$51-60$ & $101(16.32 \%)$ \\
$61-70$ & $74(11.96 \%)$ \\
$71-80$ & $13(2.10 \%)$ \\
$>80$ & $2(0.32 \%)$ \\
Sex & \\
Male & $256(41.36 \%)$ \\
Female & $363(58.64 \%)$ \\
Male:Female & $1: 1.42$ \\
Eye involved & \\
Right eye & $330(52.72 \%)$ \\
Left eye & $296(47.28 \%)$ \\
Site of pterygium & \\
Nasal & \\
Temporal & $614(98.08 \%)$ \\
\hline
\end{tabular}

We had patients from both India and Nepal. There were 313 (50.56\%) patients from Nepal mainly Rupendehi (194), Nawalparasi (51), Kapilvastu (29) and Syangja (8)districts. From India there were $306(49.43 \%)$ patients from state of Bihar and Uttar Pradesh mainly from nearby Maharajgunj (71), Gorakhpur (44), Deoria (30), Siddharthanagar (26), Kushinagar (25) and Santa Kabir Nagar (18) districts. By occupation most of patients were housewife 350 (56.54\%), followed by farmer $170(27.46 \%)$, servicemen $52(8.4 \%)$, students $32(5.17 \%)$, and businessperson $10(1.62 \%)$, driver 2 $(0.32 \%)$, builder $1(0.16 \%)$, helper $1(0.16 \%)$ and tailor 1 $(0.16 \%)$. Mean duration of presentation was $3.59 \pm 2.87$ years ranging from minimum 6 months to maximum 22 years. Pterygium was operated in right eye 330 (52.72\%) and in left eye $296(47.28 \%)$. Pterygium was found mostly on nasal side $614(98.08 \%)$ and less commonly on temporal side 12 $(1.92 \%)$. Mean size of pterygium horizontally was $3.1 \pm 1.14$ $\mathrm{mm}$ pre-operatively starting from $1 \mathrm{~mm}$ to maximum $10 \mathrm{~mm}$. Morphologically, depending on the size of pterygium, maximum patients in the present study had type 2 pterygium $(73.80 \%)$ followed by type 3 pterygium $(18.69 \%)$ and least had type 1 pterygium $(7.51 \%)$ (Table 2$)$.

\section{Table 2. Morphology of pterygium}

\begin{tabular}{lc}
\hline Parameters & N $(\%)$ \\
\hline Morphological type of pterygium \\
Type $1(<2 \mathrm{~mm})$ & $47(7.51 \%)$ \\
Type $2(2-4 \mathrm{~mm})$ & $462(73.80 \%)$ \\
Type $3(>4 \mathrm{~mm})$ & $117(18.69 \%)$ \\
Size of pterygium $(\mathbf{m m})$ & $3.15 \pm 1.14$ \\
\hline
\end{tabular}


In this series systemic illness was found $74(11.95 \%)$ patients which include hypertension 44 (7.11\%) patients, diabetes mellitus $16(2.58 \%)$ patients, diabetes and hypertension together $8(1.29 \%)$ patients, hepatitis B $2(0.32 \%)$ patients, asthma $2(0.32 \%)$ patients, HIV $1(0.16 \%)$ patient and leukaemia $1(0.16 \%)$ patient. There were other associated ocular conditions seen in $184(29.39 \%)$ eyes. Cataract was the commonest associated ocular condition found in 140 $(22.36 \%)$ eyes. Type of cataract was immature senile cataract (IMSC) in 130 eyes, posterior subcapsular cataract (PSCC) in 9 eyes and mature senile cataract (MSC) in 5 eyes. Other associated ocular conditions seen were glaucoma suspect 19 $(3.02 \%)$ eyes, pseudophakia $6(0.96 \%)$, corneal scar 4 $(0.64 \%)$ eyes, confirmed glaucoma $3(0.48 \%)$ eyes, myopia 2 $(0.32 \%)$ eyes and age related macular degeneration (ARMD) $2(0.32 \%)$ eyes.

Post operative complications were seen in 105 (16.77\%) eyes and are shown in Table 3. The most common problem seen was raised intraocular pressure (IOP) which was seen in 43 $(6.87 \%)$ eyes. Raised IOP was controlled after tapering the steroids in the most of cases. Antiglaucoma drugs were used temporarily for two weeks in $8(1.28 \%)$ cases and were discontinued later. Recurrence of pterygium was noted in 4 $(0.64 \%)$ eyes. No symblepharon was found in our study.

\section{Table 3. Postoperative complications}

\begin{tabular}{ll}
\hline Complications & N $(\%)$ \\
\hline Raised IOP & $43(6.87 \%)$ \\
Scar formation & $23(3.67 \%)$ \\
Conjunctival hyperemia & $8(1.28 \%)$ \\
Wound gapping & $6(0.96 \%)$ \\
Graft edema & $5(0.80 \%)$ \\
Subgraft hematoma & $5(0.80 \%)$ \\
Graft overlap & $4(0.64 \%)$ \\
Recurrence & $4(0,64 \%)$ \\
Conjunctival granuloma & $3(0.48 \%)$ \\
Graft retraction & $2(0.32 \%)$ \\
Cyst formation & $1(0.16 \%)$ \\
Dellen & $1(0.16 \%)$ \\
\hline
\end{tabular}

\section{DISCUSSION}

The pterygium surgery is still challenging for cornea surgeons as various surgical techniques have variable outcome in terms of recurrence, complication, and cosmetic outcomes. In this study, we have operated 652 eyes in 645 patients for primary pterygium surgery using inferior conjunctival autografting. Patients were followed up for 3 months for looking any postoperative complications and recurrence. In our study mean age of patients was 44.63 years. Which is similar to the in study done in South Africa where the mean age was 46.4 years. ${ }^{16}$ Whereas in the study done by Hwang et al. the mean age of the patients was 53.5 years ${ }^{17}$ and Kwon et al from South Korea where the mean age was 56.2 years ${ }^{18}$ This difference can be explained due to variation in exposure of risk factors. People working as farmer in rural areas are more exposed to sun and UV light in comparison to people working in offices in urban areas. Furthermore there is increased awareness as well as improvement in availability of primary eye care facilities in rural municipalities. Government of Nepal has opened a primary eye care center in each local municipality. In our study pterygium was found to be most common between 31 40 years of age group $(26.33 \%)$ which is similar to the study done by Marmamula et al, who have also found the same. In their study the most common age group 30 - 39 years $(33.30 \%){ }^{19}$

In our study female (58.64\%) were involved more than the male. Similarly result was found in other studies Kwon where women $(54.3 \%)$ were involved more than men. ${ }^{18}$ Popat KB et al have also found more female $(56 \%)$ in their study. ${ }^{15}$ Pterygium was seen most common in housewife 350 $(56.54 \%)$, followed by farmer $170(27.46 \%)$. In other study carried out by shrestha et al most patients were farmers (50\%) and laborers $(34 \%){ }^{13}$ This can be explained by the fact that India and Nepal both are agriculture based country where majority of population lives in rural areas and works in farms. Females from rural areas are also equally involved in outdoor farming activities which make them exposed to wind, dust, hot climate and UV radiation. Pterygium was diagnosed in slightly more $(53 \%)$ in left eyes. ${ }^{13}$ Whereas in our study pterygium was operated slightly more in right eye ( $52.72 \%)$ than in left eye (47.28\%) but difference is insignificant.

In our study, mean size of pterygium horizontally was $3.1 \pm$ $1.14 \mathrm{~mm}$ pre-operatively which is similar to the study carried out by Shrestha et al where the average size of the pterygium was $3.2 \pm 0.60 \mathrm{~mm}^{13}$ It is a bit larger in compare to other studies from developed countries. In our study there were patients who were presented with large 9-10 $\mathrm{mm}$ size pterygium. In the study carried out by Shusko et al preoperatively, the average extent of horizontal growth of pterygium on the cornea was $2.47 \pm 0.82 \mathrm{~mm}$ which is smaller than our study. ${ }^{20}$ This can be explained by the late presentation of diseases in rural areas of developing countries in compare to developed countries.

Recurrence rate was only in 4 eyes $(0.64 \%)$ in the present study after 3 months of follow up whereas recurrence was found in 2 eyes (4\%) by Shrestha et al in the 50 eyes after 3 months follow up. ${ }^{13}$ Syam et al had $3.3 \%$ recurrence after inferior conjunctival autografting after mean follow-up duration of 27 months. ${ }^{14}$ Koc et al have demonstrated that autografting from superior or inferior sites in primary pterygium cases showed no significant difference in recurrence rate. $^{21}$ 


\section{CONCLUSION}

Pterygium is seen more commonly in young adults in their $4^{\text {th }}$ and $5^{\text {th }}$ decade of life with slightly female predominance. Patients usually present late making the size of pterygium larger. Primary pterygium surgery using inferior conjunctival autografting is a safe and effective with very few complication and recurrence. This approach helps to preserve superior bulbar conjunctiva for future glaucoma filtration and cataract surgeries.

\section{ACKNOWLEDGEMENT}

Authors are indebted to our patients and supporting staff of OT and cornea OPD of Lumbini Eye Institute and Research Center, Bhairahawa, Nepal.

\section{REFERENCES}

1. Jaros PA, DeLuise VP. Pingueculae and pterygia. Surv Ophthalmol. 1988 Jul-Aug;33(1):41-9. doi: 10.1016/00396257 (88)90071-9.

2. Norn MS. Prevalence of pinguecula in Greenland and in Copenhagen, and its relation to pterygium and spheroid degeneration. Acta Ophthalmol (Copenh). 1979 Feb; 57(1):96105.

3. McCarty CA, Fu CL, Taylor HR. Epidemiology of pterygium in Victoria, Australia. Br J Ophthalmol. 2000 Mar; 84(3):289-92.

4. Nangia V, Jonas JB, Nair D, Saini N, Nangia P, Panda-Jonas S. Prevalence and associated factors for pterygium in rural agrarian central India. The central India eye and medical study. PLoS One. 2013 Dec 4;8(12):e82439.

5. Zhong H, Cha X, Wei T, Lin X, Li X, Li J, Cai N, Li J, Su X, Yang Y, Yu M, Yuan Y. Prevalence of and risk factors for pterygium in rural adult chinese populations of the Bai nationality in Dali: the Yunnan Minority Eye Study. Invest Ophthalmol Vis Sci. 2012 Sep 25; 53(10):6617-21.

6. Yam JCS, Kwok AKH. Ultraviolet light and ocular diseases. Int Ophthalmol. 2013;34:383-400.

7. Kwok LS, Coroneo MT. A model for pterygium formation. Cornea 1994;13:219-24.

8. $\mathrm{Ma} \mathrm{K}, \mathrm{Xu} \mathrm{L}$, Jie Y, Jonas JB. Prevalence of and factors associated with pterygium in adult Chinese: the Beijing Eye Study. Cornea. 2007 Dec;26(10):1184-6.

9. Anbesse DH, Kassa T, Kefyalew B, Tasew A, Atnie A, Desta B. Prevalence and associated factors of pterygium among adults living in Gondar city, Northwest Ethiopia. PLoS One. 2017 Mar 30;12(3):e0174450

10. Kenyon KR, Wagoner MD, Hettinger ME. Conjunctival autograft transplantation for advanced and recurrent pterygium. Ophthalmology. 1985 Nov;92(11):1461-70.
11. Koranyi G, Seregard S, Kopp ED. The cut-and-paste method for primary pterygium surgery: long-term follow-up. Acta Ophthalmol Scand. 2005 Jun;83(3):298-301.

12. Romano V, Cruciani M, Conti L, Fontana L. Fibrin glue versus sutures for conjunctival autografting in primary pterygium surgery. Cochrane Database Syst Rev. 2016 Dec 2;12(12) :CD011308.

13. Shrestha A, Bhandari S, Maharjan N, Khadka D, Pant SR, Pant BP. Inferior conjunctival autografting for pterygium surgery: an alternative way of preserving the glaucoma filtration site in far western Nepal. Clin Ophthalmol. 2012;6:315-9.

14. Syam PP, Eleftheriadis H, Liu CS. Inferior conjunctival autograft for primary pterygia. Ophthalmology. 2003 Apr;110 (4):806-10.

15. Popat KB, Sheth HK, Vyas VJ, et al. A study on changes in keratometry readings and astigmatism induced by pterygium before and after pterygium excision surgery. J Res Med Den Sci 2014;2(3):37-42.

16. Anguria $\mathrm{P}$, Ntuli S, Carmichael T. Young patient's age determines pterygium recurrence after surgery. Afr Health Sci. 2014 Mar;14(1):72-6.

17. Hwang, H.S., Cho, K.J., Rand, G. et al. Optimal size of pterygium excision for limbal conjunctival autograft using fibrin glue in primary pterygia. BMC Ophthalmol. 2018;18:135.

18. Kwon SH, Kim HK. Analysis of recurrence patterns following pterygium surgery with conjunctival autografts. Medicine (Baltimore). 2015 Jan;94(4):e518.

19. Marmamula S, Khanna RC, Rao GN. Population-based assessment of prevalence and risk factors for pterygium in the South Indian state of Andhra Pradesh: the Andhra Pradesh Eye Disease Study. Invest Ophthalmol Vis Sci. 2013;54(8):5359-66.

20. Shusko A, Schechter BA, Hovanesian JA. Pterygium Surgery Utilizing Limbal Conjunctival Autograft and Subconjunctival Amniotic Membrane Graft in High-Risk Populations. Clin Ophthalmol. 2020;14:2087-90.

21. Koc F, Demirbay P, Teke MY, et al. Primary and recurrent pterygium conjunctival autografting. Toft Gaz.2002;32:583588. 